9. Абдуллина О.А. Общепедагогическая подготовка учителя в системе высшего педагогического образования. М., 1991. Гл. 1.

10. Аниськин В.Н. Профессиональная компетентность и профессиональная компетенция преподавателя вуза: проблема разграничения понятий // Известия СНЦ РАН. 2010. Т. 12, № 3 (3) (35). С. 558-563.

11. Шамина Н.П. Формирование управленческой компетентности будущего педагога начальной школы: дис. ... канд. пед. наук. Самара. 2013. С. 27-29.

12. Богин В. Обучение рефлексии как способ формирования творческой личности // Современная дидактика: теория - практике / под ред. И.Я. Лернера, И.К. Журавлева. М., 1994. С. 153-175.

13. Семенов И.Н., Степанов С.Ю. Рефлексия в организации творческого мышления и саморазвития личности // Вопросы психологии. 1983. № 2. С. 3542.

14. Карпов А.В. Рефлексивность как психическое свойство и методика ее диагностики // Психологический журнал. 2003. Т. 24, № 5. С. 45-57.

15. Кушеверская Ю.В. Формирование рефлексивной компетентности студентов в образовательном процессе педагогического колледжа: автореф. дис. ... канд. пед. наук. Петрозаводск. 2007. 21 с.

16. Давыдов В.В., Зак А.З. Проблемы рефлексии: Современные комплексные исследования. Новосибирск: Наука, 1987. 213 с.

17. Щербакова Т.Н. Профессиональный рост учителя: формирование механизмов субъективного контроля. Ростов-на-Дону. 1994. 80 с.

\title{
PEDAGOGICAL REFLECTION DEVELOPMENT IN THE COURSE OF PROSPECTIVE ELEMENTARY SCHOOL TEACHERS' TRAINING FOR PROFESSIONAL ACTIVITY
}

(C) 2017

\author{
Sevenyuk Svetlana Aleksandrovna, candidate of pedagogical sciences, associate professor, \\ head of Psychology and Social Pedagogy Department \\ Shamina Natalya Petrovna, candidate of pedagogical sciences, \\ associate professor of Psychology and Social Pedagogy Department \\ Samara State University of Social Sciences and Education (Samara, Russian Federation)
}

\begin{abstract}
The paper deals with features of pedagogical reflection development of prospective elementary school teachers during their training at a higher education institution. The authors analyze modern requirements to personal and professional qualities of a teacher, his or her social value and worthiness caused by radical modernization and cardinal transformations of Russian system of pedagogical education. The authors show that at a high school it is important for students to change position from a consumer of information to a creator of knowledge, to develop personal features, to understand the results of his or her pedagogical activity. The paper contains advantages of such an approach of ensuring systemacy of higher pedagogical education updates. Professional activity of each teacher has to be adapted to these changes. Each teacher has to understand the environment surrounding him; s/he has to be ready for continuous self-education to increase the efficiency of the daily practical activities. In this regard the authors suppose that reflection is a necessary and a major component of pedagogical activity structure. Reflection is supposed to be teacher's personal analysis of his or her activity. The authors of the paper think that pedagogical activity has a reflexive character as a teacher who organizes pupils' activity is obliged to correct his or her actions from a pupil's position, it is obligatory to take their views into account, to see their inner world and their emotional state. On the basis of the given arguments the authors come to the conclusion that a teacher's significant professional quality is his or her ability to reflect.

Keywords: prospective teachers' training; development reflection; professional activity; pedagogical process; competence approach; pedagogical reflection development.
\end{abstract}

УДК 378:37.034.37.036

\section{О ЕДИНСТВЕ НРАВСТВЕННОГО И ЭСТЕТИЧЕСКОГО ВОСПИТАНИЯ БУДУЩИХ ПЕДАГОГОВ-ДИЗАЙНЕРОВ}

(C) 2017

Стаценко Елена Рудольфовна, кандидат педагогических наук, доцент, декан факультета искусств и сервиса Мурманский арктический государственный университет (2. Мурманск, Российская Федерация)

Аннотация. В статье проблема воспитания студентов вуза обосновывается как актуальная социальнопедагогическая проблема. Аргументируется важность гармоничного сочетания в воспитательном процессе нравственного, эстетического, трудового, физического и других направлений и видов воспитания при направляющей роли нравственного воспитания. Обосновывается важность осуществления нравственного и этического воспитания будущего педагога-дизайнера в их единстве. Раскрывается взаимосвязь Добра и Красоты как ценностных оснований нравственного и эстетического воспитания соответственно. Формирование моральных качеств студента, развитие у него эстетических вкусов и идеалов соотносится с формированием ценностной сферы его сознания. Процесс воспитания студентов вуза рассматривается как их приобщение к ценностям. Доказывается, что единство нравственного и эстетического воспитания студентов - будущих педагогов-дизайнеров есть взаимодополняемый процесс их приобщения к нравственным и эстетическим ценностям, когда независимо от конкретной ситуации нравственные ценности содержательно дополняют эсте- 
тические, а эстетические - нравственные. Обосновывается, что эффективным средством нравственного и эстетического воспитания студентов вуза в их единстве является искусство как творческое отражение, воспроизведение действительности в художественных образах. Обозначаются методы осуществления нравственного и эстетического воспитания в их единстве: беседа, дискуссия, диспут, этический диалог (аудиторная работа); читательская конференция, просмотр и последующий анализ кинофильмов, организация художественной самодеятельности, экскурсии и т.д. (внеаудиторная работа).

Ключевые слова: будущий педагог-дизайнер; студент; преподаватель; воспитание; нравственное воспитание; эстетическое воспитание; единство; ценность; добро; красота; искусство; художественный образ; метод; приобщение к ценностям; аудиторная работа; внеаудиторная работа.

Важной тенденцией в современном российском высшем образовании является обращение к проблеме воспитания студентов. Пришло понимание того, что наряду с профессиональной подготовкой необходимо формировать личность будущего специалиста, так как эффективность профессиональной деятельности во многом связана и с личностными качествами человека, такими, например, как ответственность, самостоятельность, порядочность, справедливость и т.д. Естественно, что студент, поступающий в вуз в возрасте 17-18 лет, а зачастую и старше, - это сформировавшаяся личность со своей системой взглядов, убеждений, личностных качеств. Однако процесс развития личности человека непрерывен и продолжается всю его жизнь. Большое влияние на этот процесс оказывает окружающая человека среда (социальная, культурная, информационная, образовательная и т.д.). Тем самым педагогически грамотно выстраиваемый образовательный процесс может развить в молодом человеке те положительные черты, которые у него есть, но не находят пока своего проявления, а также скорректировать отрицательные личностные проявления.

В современной научной и методической литературе представлено большое количество направлений и видов воспитания: нравственное, эстетическое, физическое, трудовое, патриотическое, гражданственное и т.д. Представляется важным гармоничное сочетание в воспитательном процессе вуза как можно большего числа данных направлений и видов. В то же время необъятное объять невозможно, и при организации воспитательной работы со студентами необходимо, на наш взгляд, ориентироваться, в том числе, и на специфику их будущей профессии. При этом заметим, что нравственное воспитание студентов должно стать тем фундаментов, на котором выстраивается вся воспитательная система вуза.

В рамках данной статьи мы обратимся к проблеме воспитания будущих педагогов-дизайнеров и остановимся на таком ее аспекте, как единство нравственного и эстетического воспитания.

Педагог-дизайнер в рамках своей профессиональной деятельности осуществляет «организацию дизайн-образования посредством формирования проектной культуры в процессе обучения и воспитания детей в дошкольных образовательных учреждениях, общеобразовательной школе и системе дополнительного образования детей и подростков, в системе средне-специального и высшего образования» [1, c. 208]. В трактовке дизайн-образования мы придерживаемся точки зрения Г.А. Горбуновой, О.П. Савельевой, которые пишут: «Дизайн-образование - это особое качество и тип образованности, в результате которого происходит воспитание проектно-мыслящего человека, в какой бы сфере социальной практи- ки он ни действовал - образовании, науке, культуре, производстве, бытовой сфере и т.д. Дизайн-образование есть системная форма организации культурнотворческой среды в образовательном учреждении, обществе, государстве» [1, с. 208]. Под дизайном мы понимаем создание проектного прообраза вещи, который объединяет утилитарные, технико-технологические, экономические и одновременно художественно-эстетические ее качества.

Педагог-дизайнер учит ребенка создавать вещи как носители нравственно-эстетических ценностей. Иными словами, он учит ребенка творить красоту, а потому педагог-дизайнер и сам должен чувствовать эту красоту, обладать эстетическим вкусом. Подлинная красота всегда связана с добром. По утверждению Т.В. Мишаткиной, добро - «это любовь, мудрость, талант, активность, гражданственность, чувство сопричастности проблемам своего народа и человечества в целом. Это вера и надежда, истина и красота. Иными словами, все то, что придает смысл человеческому существованию» [2, с. 154]. В личности педагога-дизайнера в идеале гармонично сочетаются ценности Добра (этическая ценность) и Красоты (эстетическая ценность).

Еще в Древней Греции существовало понятие «калокагатия», которое объединяло «кагатос» (нравственную ценность) и «калос» (эстетическую ценность). Христианство отождествляло и отождествляет Добро и Красоту как разные проявления единой Божественной благости. И хотя этика и эстетика Нового времени принципиально различают эти виды ценности, исходя из того, что Добро свойственно только человеку как носителю духовной мотивации своего поведения, а Красота может характеризовать все материальные предметы (природу, вещи, человека в его телесном облике), М.С. Каган обосновывает взаимосвязь нравственных и эстетических ценностей, утверждая, что личность как аксиологический субъект обладает двумя возможностями. Это ценностное осознание личности своей связи с окружающим материальным миром (естественно-природным и рукотворно-вещественным) и с миром духовным, воплощенным в других людях, в одухотворяемых человеком природных явлениях и вещах [3, c. 114].

Педагогическая деятельность по своей сути базируется на этических и эстетических ценностях. Данное положение является общепринятым и находит отражение во многих научных источниках. Так, например, Н.Н. Никитина, Н.В. Кислинская пишут: «Педагогическая деятельность как сфера духовного производства характеризуется глубоким проникновением в нее этических и эстетических начал. Этическое (нравственное) и эстетическое (прекрасное) тесно взаимосвязаны и переплетены в личности учи- 
теля, в его общении с учениками и коллегами, в отношении его к своему труду, профессии» [4, с. 42].

В научной периодике последних лет значительное место уделяется как проблеме нравственного [59], так и проблеме эстетического воспитания [10-15] студентов вузов. Заметим, что мы упоминаем лишь незначительное количество статей по данной проблематике. Необходимо отметить, что в указанных источниках не предлагаются как таковые определения нравственного воспитания и эстетического воспитания студентов вуза, поэтому, рассматривая проблему единства нравственного и эстетического воспитания студентов, мы обратились к определениям, представленным в Большом тематическом словаре по образованию и педагогике В.М. Полонского. Нравственное воспитание рассматривается в словаре как «целенаправленный процесс формирования моральных качеств личности, характера, поступков, навыков, привычек поведения. Основные компоненты, составляющие основу нравственного воспитания: нравственные знания, нравственные отношения, нравственные переживания, волевые устремления, нравственный выбор целей и средств, совершение нравственных поступков, формирование у самого себя нравственных черт личности» [16, с. 292]. Эстетическое воспитание: «процесс целенаправленного формирования вкусов и идеалов личности, развитие ее способности к эстетическому восприятию явлений действительности и произведений искусства, а также к самостоятельному творчеству» [16, с. 296].

Формирование моральных качеств студента, развитие у него эстетических вкусов и идеалов связано с формированием ценностной сферы его сознания. Ценность, представляя собой, по утверждению М.С. Кагана, значение данного предмета для субъекта, есть отношение, причем специфическое отношение, поскольку она связывает объект не с другим объектом, а с субъектом [3, с. 67].

Процесс воспитания студентов есть их приобщение к ценностям. Здесь мы основываемся на положениях, во-первых, М.С. Кагана: воспитание есть «формирование системы ценностей, с ее специфическим содержанием. <..> Воспитание есть способ превращения ценностей социума в ценности личности» [3, с. 176]; во-вторых, А.В. Бездухова, Ю.В. Лопуховой: воспитание есть приобщение человека к ценностям $[17$, с. 69]. Тем самым нравственное воспитание студентов есть их приобщение к нравственным ценностям, а эстетическое воспитание - к эстетическим ценностям. Единство нравственного и эстетического воспитания студентов - будущих педагогов-дизайнеров в данном контексте мы рассматриваем как взаимодополняемый процесс их приобщения к нравственным и эстетическим ценностям, когда независимо от конкретной ситуации нравственные ценности содержательно дополняют эстетические, а эстетические - нравственные.

Эффективным средством нравственного и эстетического воспитания будущих педагогов-дизайнеров, осуществляемого в их единстве, является искусство как творческое отражение, воспроизведение действительности в художественных образах. Это художественная литература, музыка, изобразительное искусство, театр, кино и т.д. Например, при знакомстве студентов с различными произведениями искусства преподаватель раскрывает будущим педагогам эстетическую сущность произведения в единстве с нравственным его содержанием. Студент учится не только воспринимать красоту произведения искусства (эстетическая ценность), но и видеть в нем нравственный смысл, выражающийся в нравственных ценностях добра, справедливости, милосердия и т.д. Используя в образовательном процессе произведения искусства, преподаватель помогает будущему педагогу увидеть красоту человеческих отношений, в основаниях которых находятся любовь, сопереживание другому, забота о нем; показывает гармонию справедливости и милосердия, свободы и ответственности.

Искусство раскрывает, обобщает, систематизирует исторически складывающийся опыт эстетических и этических отношений человека к действительности и передает его в доступном множеству людей виде. И поскольку искусство концентрированно, содержательно, насыщенно, емко отражает и выражает в художественной форме как эстетическую, так и нравственную сущность действительности, постольку оно является действенным средством приобщения студента - будущего педагога-дизайнера как к нравственным, так и к эстетическим ценностям.

Например, музыка имеет непосредственное воспитательное значение, так как совместные переживания возвышенных, героических, лирических чувств, заключенных в музыке, объединяют и сплачивают студентов. Воспитательное влияние музыки тем сильнее, чем более развит музыкальный слух, художественная требовательность к музыкальным произведениям, чем чаще студенты вовлекаются в практическую, исполнительную деятельность.

Такое же большое значение в деле нравственного и эстетического воспитания в их единстве имеет изобразительное искусство. Средствами живописи, скульптуры, графики, архитектуры выражается красота жизни, природы и общества, отвергается все низкое и отвратительное, выражаются самые высокие мысли, чувства и стремление людей. Произведения изобразительного искусства зовут к борьбе за прекрасное. Способность понимать и тонко чувствовать прекрасное в изобразительном искусстве, способность создавать прекрасное в живописи, скульптуре, графике начинает формироваться в процессе собственной изобразительной деятельности, в процессе познания изобразительного искусства. Что особенно актуально для будущих педагогов-дизайнеров.

Пробуждение гаммы эмоций, связанных с эстетическими переживаниями студентов, достигается организацией активной деятельности самих студентов, которая является условием проявления и развития у них эстетических переживаний. Мы полагаем, что в контексте единства нравственного и эстетического воспитания студентов важно добиваться того, чтобы нравственные и эстетические идеалы были неразрывно связаны между собой. Следует обращать внимание студентов на красоту совершаемых ими самими и окружающими их людьми нравственных поступков, среди которых, например, такие, как проявление патриотизма, трудолюбия, дисциплинированности, смелости, находчивости, заботы о людях. Эстетические переживания студентов - будущих педагогов-дизайнеров на занятиях, в процессе внеауди- 
торной деятельности и в повседневной жизни связаны с развитием у них способности вычленять, осознавать и ценить прекрасное в окружающем их мире, с развитием стремление участвовать в создании прекрасного. Переживания прекрасного в жизни развивают у студентов и способность более глубокого понимания прекрасного в искусстве.

Нравственное и эстетическое воспитание в их единстве осуществляется как на лекционных и семинарских занятиях, так и в процессе внеаудиторной воспитательной работы со студентами. Мы полагаем, что практически все дисциплины, изучаемые будущими педагогами-дизайнерами, обладают возможностями осуществления нравственного и эстетического воспитания в их единстве.

Например, на лекционных занятиях по философии студенты знакомятся с понятием «ценность», с нравственными и эстетическими ценностями, а на семинарских занятиях осмысливают данные ценности, наполняют их личностным содержанием. Здесь, с нашей точки зрения, эффективны методы обучения и воспитания, которые предполагают взаимодействие преподавателя и студентов, а также самих студентов в диалоге. Это, прежде всего, такие методы, как беседа, дискуссия, диспут, этический диалог. Включаясь в разнообразные формы решения проблем на основе диалогового общения, пишет Ю.Н. Кулюткин, человек приобретает определенный опыт и определенную культуру совместного поиска решений: у него развивается способность самостоятельно ставить вопросы и отвечать на вопросы других людей; он становится более терпимым к разным мнениям, которые высказываются в группе по одному и тому же вопросу; он вырабатывает у себя установку не только на то, чтобы учитывать мнение другого, но и на то, чтобы находить точки соприкосновения между мнениями участников диалога, открывать в них нечто общее, входить в единое смысловое поле, возникающее в многоголосице дискуссий и обсуждений [18, с. 307].

Среди названных выше методов особое место, с нашей точки зрения, занимает этический диалог. В.П. Бездухов подчеркивает, что этический диалог, «пробуждая у студентов интерес к этике, формируя у них потребность в этических и моральных знаниях, способствует усвоению будущими учителями сущности категорий педагогической этики, норм и принципов педагогической морали, их теоретическому осмыслению, показывает правильность и точность их употребления в общении и вред смешения понятий при неправильном их применении» [19, с. 87]. Мы полагаем, что в рамках проблематики данной статьи такое определение может быть дополнено в том смысле, что этический диалог обеспечивает развитие как этических, так и эстетических знаний студентов, потребность в нравственно-эстетическом осмыслении педагогических проблем. Благодаря использованию метода этического диалога возможно развитие нравственных и эстетических представлений студентов о добре, красоте, истине, прекрасном и т.д.

Во внеаудиторной работе со студентами эффективными методами осуществления нравственного и эстетического воспитания в их единстве являются читательская конференция, совместный со студентами просмотр и последующий анализ кинофильмов, организация художественной самодеятельности студентов, совместное прослушивание музыкальных произведений, посещение театра, экскурсии в музеи на выставки, в том числе и виртуальные экскурсии.

Систематически и целенаправленное осуществление нравственного и эстетического воспитания будущих педагогов-дизайнеров способствует формированию личности учителя, способного реализовывать в своей жизни и профессиональной деятельности ценности добра и красоты в их гармоническом единстве.

\section{СПИСОК ЛИТЕРАТУРЫ:}

1. Горбунова Г.А., Савельева О.П. К вопросу о непрерывности дизайн-образования: проблемы и перспективы // Вестник Оренбургского государственного университета. 2015. № 5 (180). С. 206-211.

2. Мишаткина Т.В. Добро и зло // Этика / под ред. Т.В. Мишаткиной, Я.С. Яскевича. Мн.: Новое знание, 2002. С. 153-176.

3. Каган М.С. Философская теория ценности. СПб.: Петрополис, 1997. 205 с.

4. Никитина Н.Н., Кислинская Н.В. Введение в педагогическую деятельность. М.: ACADEMIA, 2004. $2016 \mathrm{c}$.

5. Антонова Г.В., Левченко Н.В., Маслов С.И. Духовно-нравственное воспитание студентов в процессе изучения педагогических дисциплин в вузе // Известия Тульского государственного университета. Гуманитарные науки. 2014. № 4-1. С. 87-92.

6. Бабаева А.Д. Педагогические основы нравственного воспитания студентов вуза // Наука, новые технологии и инновации. 2016. № 11. С. 275-277.

7. Бахчиева О.А. Проблема духовно-нравственного воспитания будущего учителя в процессе профессиональной подготовки // Наука и бизнес: пути развития. 2013. № 4 (22). С. 122-124.

8. Спицына Л.Г. Проблемы и перспективы духовно-нравственного воспитания студентов вуза - будущих педагогов // Таврический научный обозреватель. 2016. № 1-3 (6). С. 44-47.

9. Товарищева Ф.Д. Нравственное воспитание будущих учителей как социально-педагогический процесс // Современные наукоемкие технологии. 2010. № 7. C. 285-289.

10. Валеева Р.А., Каркина С.В. Эстетическое воспитание студента вуза средствами интеграции искусств как фактор развития субъектности // Образование и саморазвитие. 2014. № 3 (41). С. 51-54.

11. Ипполитова Н.В., Стерхова Н.С. Структурносодержательный анализ процесса эстетического воспитания студентов педагогического вуза // Вестник Ишимского государственного педагогического института им. П.П. Ершова. 2012. № 5 (5). С. 66-73.

12. Симонкина Ю.С. Эстетическое воспитание студентов в образовательном процессе вуза // Научные итоги года: достижения, проекты, гипотезы. 2011. № 1-1. C. 183-187.

13. Стерхова Н.С. Эстетическое воспитание студентов педагогического вуза в контексте структурного анализа // Актуальные проблемы гуманитарных и социально-экономических наук. 2012. № 6. С. 44-49.

14. Хаитов Л.А. Значение эстетического воспитания в развитии личности студента педагогического вуза // Наука. Мысль. 2014. № 10. С. 40-44. 
15. Харьковская Е.В., Мешков В.А. Роль эстетического воспитания студентов в образовательновоспитательном пространстве вуза // Наука. Искусство. Культура. 2014. № 4. С. 205-209.

16. Полонский В.М. Большой тематический словарь по образованию и педагогике. М.: Народное образование, 2017. $840 \mathrm{c}$.

17. Бездухов А.В., Лопухова Ю.В. Воспитание как движение, превращающее возможное в действительное // Известия РАО. 2011. № 1 (17). С. 66-75.
18. Кулюткин Ю.Н. Диалог как предмет педагогической рефлексии // Ценностные ориентиры и когнитивные структуры в деятельности учителя / Ю.Н. Кулюткин, В.П. Бездухов. Самара: СГПУ, 2002. C. 274-329.

19. Бездухов В.П. Теоретические проблемы становления гуманистического стиля педагогической деятельности будущего учителя. Самара: СамГПИ, 1992. $104 \mathrm{c}$.

\title{
THE UNITY OF MORAL AND AESTHETIC EDUCATION OF PROSPECTIVE TEACHER-DESIGNERS
}

(C) 2017

\author{
Statsenko Elena Rudolfovna, candidate of pedagogical sciences, \\ associate professor, head of Arts and Service Faculty \\ Murmansk Arctic State University (Murmansk, Russian Federation)
}

\begin{abstract}
In the paper the problem of university students' education is considered to be an urgent social and pedagogical problem. The authors think that it is important to combine moral, aesthetic, labor, physical, etc education in the educational process of a higher education institution. The importance of moral and ethical education of prospective teacher-designers is substantiated. The relationship between Good and Beauty is revealed as the value basis for moral and aesthetic education. Students' moral qualities development, their aesthetic tastes and ideals development correlates with the development of the value sphere of their consciousness. The process of university students' education is seen as their involvement in values. The authors prove that the unity of moral and aesthetic education of students - prospective teachers of design - is a complementary process of their involvement in moral and aesthetic values, when, regardless of a particular situation, moral values are meaningfully complemented by aesthetic ones while aesthetic values - by moral ones. The authors think that an effective means of moral and aesthetic education of university students is art as creative reflection, reproduction of reality in artistic images. The paper contains methods of moral and aesthetic education: talk, discussion, debate, ethical dialogue (classroom work); reading conference, viewing and subsequent analysis of movies, organizing amateur performances, excursions, etc. (extracurricular work).
\end{abstract}

Keywords: prospective teacher-designer; student; teacher; education; moral education; aesthetic education; unity; value; good; beauty; art; artistic image; method; values; classroom work; extracurricular work.

УдК 378.09

\section{ФОРМИРОВАНИЕ ЭКЗИСТЕНЦИАЛЬНЫХ АСПЕКТОВ ПРОФЕССИОНАЛЬНОЙ КОМПЕТЕНТНОСТИ БУДУЩИХ СОТРУДНИКОВ УГОЛОВНО-ИСПОЛНИТЕЛЬНОЙ СИСТЕМЫ}

(C) 2017

\author{
Тарасова Светлана Александровна, кандидат психологических наук, \\ доцент кафедры пенитенциарной психологии и педагогики \\ Самарский юридический институт ФСИН России (2. Самара, Российская Федераиия)
}

Аннотация. В статье обсуждается проблема профессиональной компетентности сотрудников уголовноисполнительной системы. Отмечается необходимость формирования у них готовности к трудностям на жизненном и профессиональном пути. Экзистенциальный аспект определяется как составная часть целостной профессиональной компетентности. В его содержание входит экзистенциальная установка по отношению к своей будущей профессиональной деятельности и жизни в целом. Экзистенциальная установка определяется как готовность будущего специалиста к саморазвитию и самосовершенствованию себя в качестве субъекта своей жизни и профессионального развития. В работе подчеркивается, что экзистенциальная установка выступает как духовный ресурс и способствует сохранению профессиональной вовлеченности будущего сотрудника уголовно-исполнительной системы в трудной жизненной ситуации. Отмечается, что экзистенциальная установка формируется в процессе развития рефлексии. В статье предлагаются формы учебной работы: экзистенциальный диалог, эссе, решение ситуационных задач. Дается краткая характеристика данных форм работы и приводятся конкретные примеры заданий. Называются показатели эффективности проводимой работы: появление у обучаемых интереса к духовной стороне жизни, к проблемам смысла жизни и профессиональной деятельности, ответственности за свой выбор.

Ключевые слова: профессиональная компетентность; профессиональная деятельность; экзистенциальные аспекты компетентности; уголовно-исполнительная система; экзистенциальная установка; субъект; рефлексия; профессиональная вовлеченность; экзистенциальный диалог; эссе; ситуационная задача; духовный ресурс; трудная жизненная ситуация; формы учебной работы. 